\title{
Beat the heat: Culex quinquefasciatus regulates its body temperature during blood-feeding
}

\author{
Joanna M. Reinhold1, Ryan Shaw1,2 and Chloé Lahondère1,3,4,5
}

1 Department of Biochemistry, Virginia Polytechnic Institute and State University, Blacksburg, VA, 24061, USA.

2 Department of Biological Sciences, Virginia Polytechnic Institute and State University, Blacksburg, VA, 24061, USA.

3 The Fralin Life Science Institute, Virginia Polytechnic Institute and State University, Blacksburg, VA, 24061, USA.

4 The Global Change Center, Virginia Polytechnic Institute and State University, Blacksburg, VA, 24061, USA.

5 Department of Entomology, Virginia Polytechnic Institute and State University, Blacksburg, VA, 24061, USA.

Keywords: thermography, thermal stress, disease vector mosquito, hematophagy, evaporative cooling, heterothermy

To whom all correspondence should be addressed:

Chloé Lahondère

Department of Biochemistry

Virginia Polytechnic Institute and State University

Blacksburg, VA, 24061, USA

E-mail: lahonder@vt.edu 


\section{Highlights}

- Mosquitoes have evolved to cope with heat stress associated with warm blood ingestion

- Culex quinquefasciatus displays heterothermy while blood-feeding

- The abdominal temperature decreases due to evaporative cooling using urine droplets

- Overall, the mosquito body temperature is much cooler than the ingested blood 


\section{Abstract}

81 Mosquitoes are regarded as one of the most dangerous animals on earth. As they are responsible

82 for the spread of a wide range of both human and animal diseases, research of the underlying

83 mechanisms of their feeding behavior and physiology is critical. Among disease vector

84 mosquitoes, Culex quinquefasciatus, which is a known carrier of West Nile virus and Western

85 Equine Encephalitis, remains relatively understudied. As blood sucking insects, adaptations (either

86 at the molecular or physiological level) while feeding on warm blood is crucial to their survival,

87 as overheating can result in death due to heat stress. Our research aims to study how $C x$.

88 quinquefasciatus copes with heat associated with the ingestion of a warm blood-meal and to

89 possibly uncover the adaptations this species uses to avoid thermal stress. Through the use of

90 thermographic imaging, we analyzed the body temperature of $C x$. quinquefasciatus while blood

91 feeding. Infrared thermography has allowed us to identify a cooling strategy, evaporative cooling

92 via the production of fluid droplets, and an overall low body temperature in comparison to the

93 blood temperature during feeding. Understanding Cx. quinquefasciatus' adaptations and various

94 strategies that they employ to reduce their body temperature while blood-feeding constitutes the

95 first step towards the discovery of potential targets of opportunity for their control. 


\section{INTRODUCTION}

Mosquitoes are the deadliest animal on the planet, killing an estimated 1 million people per

year (WHO, 2020). Mosquitoes vector several pathogens responsible for devastating diseases,

106 such as malaria, spread by Anopheles spp., and dengue, chikungunya, and Zika, spread primarily

107 by Aedes spp (Reviewed by Reinhold et al., 2018; WHO, 2020). West Nile virus (WNV), which

108 has had an increase in cases by $25 \%$ in the last few years, and other diseases causing encephalitis

109 are mainly spread by Culex spp. (CDC, 2019; WHO, 2020). Vaccines and treatments have either

110 not been developed or are limited in efficacy for these diseases, thus vector control remains the

111 primary method of prevention (WHO 2020). Culex quinquefasciatus (Say, 1823) (previously

112 Culex pipiens fatigans), or the southern house mosquito, is part of the Culex pipiens complex and

113 inhabits tropical and subtropical regions of the World including the Americas, Africa, the Middle

114 East, Asia and Australia (Samy et al., 2016). As a part of this complex, it is one of the primary

115 vectors for WNV (Kent et al., 2010; Molaei et al., 2007), St. Louis encephalitis (SLE) (Diaz et al.,

116 2013; Meyer et al., 1983), Western equine encephalitis (WEE) in China (Wang et al., 2012) and

117 Japanese encephalitis (dos Santos Malafronte, 2003; Nitatpattana et al., 2005). This species also

118 vectors an insect-specific virus, Culex flavivirus (CxFV) (Hoyos-Lopez et al., 2016, Farfan-Ale et

119 al., 2010), which may increase the likelihood of infection and the transmission of WNV (Kent et

120 al., 2010; Newman et al., 2011). Moreover, Cx. quinquefasciatus is the primary vector for the

121 parasite Wuchereria bancrofti, the causative agent of lymphatic filariasis (Reviewed by Farajollahi

122 et al., 2011; Triteeraprapab et al., 2000; Vythilingam et al, 2005). While this species is an

123 important disease vector, it is often ignored in favor of research for Cx. pipiens. This could be

124 largely due to the geographic distribution of the two species, Cx. pipiens occupying more northern,

125 and, often, more wealthy countries than Cx. quinquefasciatus (Vinogradova, 2000). Climate 
change could potentially affect the distribution of $C x$. quinquefasciatus, allowing it to spread further north into the US (Samy et al., 2016). This species feeds primarily on birds, taking a blood meal from mammals (typically humans and dogs) occasionally (Garcia-Rejon et al., 2010, Molaei et al., 2007). However, depending on the region the species is in and host availability, it has also been described as anthropophilic (Dixit et al., 2001; Hamon, 1963; Subra, 1970). This species is nocturnal and is commonly found in urban areas, feeding both endo- and exophagously (Hamon, 1963; Subra, 1970), and they will often take more than one blood meal, increasing chances for pathogen transmission (Subra, 1981). Although this is a species that feeds exclusively on warm-

134 blooded vertebrates (particularly birds, which tend to have warmer body temperatures than 135 humans), the mechanism by which this mosquito tolerates a warm blood meal several times in its 136 lifetime is unknown. a stable body temperature and are dependent on the environmental temperature. All insects have an optimum temperature at which they can perform properly (Mellanby, 1939; Upshur et al.,

141 2019). However, since environmental temperature is not consistent, animals must adjust to prevent

142 freezing or desiccation. Insects are particularly vulnerable to temperature changes as their open 143 circulatory and respiratory systems leave them susceptible to desiccation (Headlee, 1914; Rolandi 144 et al., 2014). Many insects have evolved strategies for surviving through or avoiding cold 145 temperatures, which range from moving to a warmer area (i.e., basking) (Kent et al., 2004) to 146 physiological changes (e.g., diapause, cryoprotectants, etc.) (Heinrich, 1995) to actively moving 147 muscles, particularly flight muscles, in order to produce heat (i.e., shivering) (Esch, 1988; Heinrich 148 and Kammer, 1973). On the other hand, an ambient temperature that is too high can cause the 
149 insect to slow activity to avoid overheating and desiccation (Heinrich and Esch, 1994; Upshur et

150 al., 2019). Bumblebees (Bombus vosnesenskii) are known to transfer heat from the thorax to the

151 abdomen (or vice versa) in order to cool the thorax (or abdomen) when reaching a high temperature

152 (Heinrich 1976). Additionally, Heinrich showed that honeybees (Apis mellifera) use evaporative

153 cooling by regurgitating and releasing droplets through the ventral portion of the head to evaporate

154 (1980a) and that these bees cool their thorax by transferring heat to the head, which can then cool

155 with evaporative cooling (1980b). However, some insects, such as blood-sucking insects, have to

156 face a sudden increase of their body temperature associated with blood intake from a warm-

157 blooded host (Benoit et al., 2011; Beyenbach and Piermarini 2011).

Hematophagous insects have developed a necessity to feed on blood. These insects may

159 need a blood meal because it is a sole nutrient source, like in kissing bugs (Rabinovich et al.,

160 2011), or for advancement to the next life stage, like in bed bugs (Reinhardt and Siva-Jothy, 2007),

161 or for nutrients in egg development, like in female mosquitoes (Reviewed by Adams, 1999; Gulia-

162 Nuss et al., 2015). While blood-feeding is already a risky behavior due to host defenses (Vinauger

163 et al., 2018), insects that feed on warm blooded vertebrates must face the risk of thermal stress in

164 addition to evading host defenses (Beyenbach and Piermarini, 2011). However, some species have

165 developed various coping mechanisms to avoid overheating during the sudden intake of a hot

166 liquid (Benoit et al., 2019). Insects can cool their body temperature during feeding using

167 countercurrent heat exchange, like in Rhodnius prolixus (Lahondère et al., 2017), or evaporative

168 cooling, as in Anopheles stephensi (Lahondère and Lazzari, 2012). Another method consists of

169 synthesizing heat shock proteins (HSPs) to prevent damage caused by heat stress post-feeding,

170 which is used in Aedes aegypti (Benoit et al., 2011; Lahondère and Lazzari, 2012), and Cx. pipiens

171 (Benoit et al., 2011). However, to our knowledge, nothing is known about the response to blood 
172 intake in the closely related species, $C x$. quinquefasciatus. In this study, we seek to determine how

173 Cx. quinquefasciatus copes with the thermal stress associated with the intake of a warm blood

174 meal using experimental blood feeding coupled with thermography. This allowed us to follow the

175 evolution of the body temperature of the females while feeding and identify possible cooling 176 mechanism.

\section{MATERIALS AND METHODS}

\subsection{Mosquitoes}

Cx. quinquefasciatus Say (Diptera: Culicidae) eggs (NR-43025, Culex quinquefasciatus, strain JHB) were received from the Center for Disease Control and Prevention (Atlanta, GA).

Mosquitoes were reared from eggs, which were collected as rafts from the previous generation and hatched in a larval tray (BioQuip Products, Rancho Dominguez, CA) containing deionized water and Hikari First Bites powdered fish food (Kyori Food Industries, Japan). Mosquitoes were maintained in a climatic chamber at $26 \pm 1{ }^{\circ} \mathrm{C}, 70 \%$ humidity and a 12:12 light cycle. The larvae were maintained in the trays and were isolated within 24 hours of pupation and then transferred to

187 containers (BioQuip Products, Rancho Dominguez, CA) until emergence. The mosquitoes had ad libitum access to cotton balls soaked in $10 \%$ sucrose solution, which was removed before the

189 experiments to increase the females' motivation to take a blood-meal. The females used for the 190 study were 6-10 days old and starved for 24 hours before testing.

\subsection{Experimental Blood Feeding}

Mosquitoes were released into a covered $8 \times 8 \times 8$ " metal collapsible cage (BioQuip

194 Products, Rancho Dominguez, CA) and allowed to feed on adult bovine blood (Lampire Biological 
195 Laboratories, Pipersville, PA). Blood was placed into a water bath-heated glass blood feeder (D.E.

196 Lillie Glassblowers, Atlanta, GA, USA), covered with a Parafilm membrane (Bemis Company,

197 Inc, Neenah, WI, USA). The water bath (Jublo Corio Open Heating Bath Circulators, Thomas

198 Scientific, Swedesboro, NJ) was heated to $41^{\circ} \mathrm{C}$, and the blood was warmed to $37 \mp 1{ }^{\circ} \mathrm{C}$ before

199 mosquitoes were released in the cage (Fig. 1). The mosquitoes that fed on the membrane were

200 filmed using a FLIR T540 thermographic camera (FLIR Systems, Wilsonville, OR) at a 30 frames

201 / second rate.

202

203

\subsection{Video and Data Analyses}

The videos (in .csq format) recorded with the thermographic camera were analyzed using

205 the ResearchIR software (FLIR). For each mosquito, a region of interest (ROI) point was selected

206 on the center of head, thorax, and abdomen. The software tracked the changes and evolution of the

207 body temperature of the 3 ROIs during blood-feeding, frame by frame. For each mosquito, 10

208 frames were randomly selected per body segment and averaged for each mosquito. These data

209 were then pooled $(\mathrm{N}=10)$ and were compared with pairwise Student $t$-tests using the software $\mathrm{R}$

210 (R software, version 3.6.3).

\section{RESULTS}

213 Prior to landing on the blood feeder, the body temperature $\left(\mathrm{T}_{b}\right)$ of the mosquito matched the

214 ambient temperature ( $\left.\mathrm{T}_{a}\right)$ (Figure 2A), and the temperature of the head $\left(\mathrm{T}_{h}\right)$, the thorax $\left(\mathrm{T}_{t h}\right)$, and 215 the abdomen (Tab) were all within one degree Celsius of each other (Figure 2A'). After landing, 216 the mosquito quickly warmed up purely based on contact with the feeder. Once feeding began, $\mathrm{T}_{h}$, $217 \mathrm{~T}_{t h}$, and $\mathrm{T} a b$ gradually increased (Figure $2 \mathrm{~B}$ ), and the temperatures of the three sections were 
218 increasingly different, a phenomenon known as heterothermy (Figure 2B'). As feeding continues,

$219 \mathrm{~T}_{h}\left(30.8 \pm 1.1^{\circ} \mathrm{C}\right)$ was significantly higher than $\mathrm{T}_{t h}\left(29.8 \pm 1.1^{\circ} \mathrm{C}\right)($ Student $t$ test, $\mathrm{t}=7.4867, \mathrm{df}=$

2209 , p-value $=<0.001)$ and $\mathrm{T}_{a b}\left(28.8 \pm 1.1^{\circ} \mathrm{C}\right)($ Student $t$ test, $\mathrm{t}=10.377, \mathrm{df}=9, \mathrm{p}$-value $=<0.001)$.

$221 \mathrm{~T}_{t h}$ and $\mathrm{T}_{a b}$ were also significantly different from one another (Student $t$ test, $\mathrm{t}=6.0507$, df $=9$, p-

222 value $=<0.001$ ) (Figures 3 and 4). Interestingly, Cx. quinquefasciatus' ${ }^{\mathrm{T}} h$ was lower than other

223 hematophagous insects when feeding on blood at the same temperature (i.e., $\left.37^{\circ} \mathrm{C}\right)($ Table 1$)$. In

224 some mosquitoes, we also noticed the excretion of droplets at the end of the abdomen during

225 feeding (i.e., prediuresis), some of which remained attached to the tip of the abdomen (Figure 5A).

226 Retaining the droplet resulted in a decrease in Tab (Figure 5B). After the mouthparts were retracted

227 from the feeder membrane, $\mathrm{T}_{b}$ gradually decreased and began to return to $\mathrm{T}_{a}$ (Figure $2 \mathrm{C}$ ). After

228 feeding stopped, $\mathrm{T}_{h}, \mathrm{~T}_{t h}$, and $\mathrm{T}_{a b}$ were close to ambient temperature (Figure $2 \mathrm{C}^{\prime}$ ). We also

229 measured the duration of feeding in $C x$. quinquefasciatus (Table 1). At greater than 3 minutes on

230 average, this species took slightly longer than most other warm-blood feeding mosquitoes to

231 imbibe a blood meal at $37^{\circ} \mathrm{C}$. However, it remains much less than the mosquito Cx. territans,

232 which primarily feeds on cold-blooded animals including frogs and snakes, or other

233 hematophagous insects (Table 1).

\section{DISCUSSION}

In the present study, we showed that $C x$. quinquefasciatus displays heterothermy, a

237 temperature gradient along the body segments, while feeding on warm blood. This has been

238 observed in several hematophagous insect species, but the underlying mechanisms can vary

239 (Benoit et al., 2019; Lahondère and Lazzari, 2013). Countercurrent heat exchange is mostly seen

240 in the literature as a method of heat conservation (e.g., Casey, 1988; Heinrich, 1995), but 
241 Lahondère et al. (2017) showed that the kissing bug, Rhodnius prolixus, uses countercurrent heat

242 exchange to cool its abdomen down while feeding. Cool hemolymph is pumped from the abdomen

243 to the head through the heart and aorta, which comes into contact with the esophagus in the head.

244 The hot ingested blood circulating into the esophagus transfers some of its heat to the hemolymph

245 in the aorta, which helps to cool the blood before it reaches the crop. Another strategy, evaporative

246 cooling, consists of excreting and retaining droplets of fluid in order to cool down (Heinrich,

247 1980a; Prange, 1996). Several hematophagous arthropods, including sandflies (Sadlova et al.,

248 2013), mosquitoes (Lahondère and Lazzari, 2012) and ticks (Lazzari et al., 2020), use this method

249 to cool down during blood intake. Mosquitoes use prediuresis droplets for evaporative cooling, in

250 which the insect excretes a droplet composed of fresh blood and urine and holds it at the tip of the

251 abdomen to cool down (Lahondère and Lazzari, 2012). In An. stephensi, prediuresis is observed

252 during blood intake, and keeping the droplet to perform evaporative cooling occurs in most

253 individuals (Lahondère and Lazzari, 2012; 2013). In the present study, we noted only a small

254 percentage of $C x$. quinquefasciatus displaying this behavior. Future experiments in which

255 mosquitoes are fed with blood at different temperatures will inform whether evaporative cooling

256 occurrence is dependent on the temperature of the host blood.

While most species of hematophagous insects have a head temperature close to the

258 temperature of the blood while feeding, here, we noted that Cx. quinquefasciatus' head

259 temperature was much lower than that of the blood. Lahondère and Lazzari showed a few degree

260 difference between the blood temperature and the mosquito head temperature (in this case, Ae.

261 aegypti and An. stephensi) (2012) or the tsetse fly Glossina morsitans $\left(<2{ }^{\circ} \mathrm{C}\right.$ difference) (2015),

262 whereas we observed a much larger difference $\left(\sim 6^{\circ} \mathrm{C}\right.$ on average). This suggests that $C x$.

263 quinquefasciatus has developed a way to cool blood down before it reaches the head. While this 
264 has not been seen in mosquitoes, cooling of the head has been seen in honeybees, which use

265 evaporative cooling by releasing droplets from the ventral portion of the head (Heinrich, 1980a).

266 We put forth the hypothesis that the ingestion pumps in Cx. quinquefasciatus may have a

267 specialized function that may play a role in this. Investigating the pumps' anatomy and function

268 during blood ingestion will provide insights into the mechanisms underlying heterothermy in $C x$.

269 quinquefasciatus (Kikuchi et al., 2018; Lahondère et al., 2017). Another possibility is that $C x$.

270 quinquefasciatus could be controlling its body temperature by intaking the blood more slowly than

271 other mosquito species. Chadee et al. (2002) found both fast and slow feeders in Ae. aegypti (less

272 than or greater than 2 minutes, respectively), whereas $C x$. quinquefasciatus took an average of 3

273 minutes to take a full meal (Table 1). This slower feeding time could allow the blood to lose heat

274 through the cuticle of the stylets as the mosquito ingests the blood meal.

To avoid heat stress associated with the ingestion of a warm blood meal, mosquitoes can

276 shift their host preference and select relatively cooler blood to feed on. We made some

277 observations of mosquitoes seemingly preferring to feed on the outer rim of the blood feeder,

278 where the blood is slightly cooler. This behavior has been seen with hosts as well, as Oduola and

279 Awe (2006) found that Cx. quinquefasciatus prefers to feed on the foot and ankle rather than the

280 calf and thigh, which could be due to odorants produced by the foot, but it may also be affected by

281 the lower temperature of the extremities (Aminoff et al., 2018). Host or biting site selection, i.e.,

282 preferring to feed on the lowest temperature area available, may also contribute to evaporative

283 cooling droplet formation, where mosquitoes forced to feed on warmer blood may be more likely

284 to form a droplet. Comparing the feeding behavior of $C x$. quinquefasciatus at varying temperatures

285 will allow us to test this hypothesis. It is worth mentioning that when we analyzed the feeding 
activity of the closely related cold-blooded feeding mosquito, Culex territans, we found that this species takes 13 times longer to feed to repletion than $C x$. quinquefasciatus (Table 1). function as chaperone proteins to prevent damage to existing proteins during times of stress, to recover from ingestion of a hot blood meal. Because the production of HSPs in response to thermal stress is a highly conserved physiological response to heat stress throughout the animal kingdom (Pereira et al., 2017), and Cx. pipiens has been shown to use these proteins after ingesting a hot blood-meal (Benoit et al., 2011), we suggest that $C x$. quinquefasciatus might also respond to heat

294 stress in this way. Tsetse flies have been shown to synthesize HSPs (Roma et al., 2019) and several mosquito species, including Ae. aegypti and Culex pipiens, use this method to recover from the stress caused by rapid intake of a warm meal (Benoit et al., 2011; Lahondère and Lazzari, 2012). of HSP70 (Paim et al. 2016). Moreover, several species of hard and soft ticks also synthesize HSPs to recover from heat stress (Guilfoile and Packila, 2004; Busby et al. 2012; Oleaga et., 2017). It is thus likely that $C x$. quinquefasciatus is synthesizing HSPs in response to the intake of a hot blood meal in addition to evaporative cooling and possibly other cooling mechanisms yet unknown.

\section{CONCLUSIONS}

305 knowledge, this study is the first focusing on the thermal biology of this mosquito species. We

306 showed that this mosquito cools down during blood-feeding in part via evaporative cooling of 307 urine droplets. Understanding the biology of this mosquito, particularly of its feeding behavior and 308 physiology, can lead to more integrative pest management methods in order to control this vector. 
Conflict of interest

311 The authors have no conflict of interest to disclose.

\section{Acknowledgements}

314 We are grateful to members of the Vinauger lab and the Lahondère lab for mosquito colony care.

315 The following reagent was provided by Centers for Disease Control and Prevention for distribution 316 by BEI Resources, NIAID, NIH: Culex quinquefasciatus, Strain JHB, Eggs, NR-43025. Figure 1

317 was created with BioRender.com. Funding sources: The Global Change Center (C.L. and R.S), the

318 Fralin Life Sciences Institute (C.L.) and the Department of Biochemistry (C.L.) at Virginia Tech.

319

320

321

322

323

324

325

326

327

328

329

330

331

332

333

334

335

336

337

338

339

340

341

\section{References}

Adams, T. S. (1999). Hematophagy and hormone release. Annals of the Entomological Society of America, 92(1), 1-13.

Aminoff, M. J., Boller, F., Swaab, D. F., Romanovsky, A. A., Garami, A. et al. (2018). Thermoregulation: from basic neuroscience to clinical neurology. ed. Andrej A. Romanovsky, Elsevier. 496pp.

Balvín, O., Munclinger, P., Kratochvíl, L., \& Vilímová, J. (2012). Mitochondrial DNA and morphology show independent evolutionary histories of bedbug Cimex lectularius (Heteroptera: Cimicidae) on bats and humans. Parasitology Research, 111(1), 457-469.

Benoit, J. B., Lopez-Martinez, G., Patrick, K. R., Phillips, Z. P., Krause, T. B. et al. (2011). Drinking a hot blood meal elicits a protective heat shock response in mosquitoes. Proceedings of the National Academy of Sciences, 108(19), 8026-8029.

Benoit, J. B., Lazzari, C. R., Denlinger, D. L., \& Lahondère, C. (2019). Thermoprotective adaptations are critical for arthropods feeding on warm-blooded hosts. Current opinion in insect science, 34, 7-11. 
Beyenbach, K. W., \& Piermarini, P. M. (2011). Transcellular and paracellular pathways of transepithelial fluid secretion in Malpighian (renal) tubules of the yellow fever mosquito Aedes aegypti. Acta Physiologica, 202(3), 387-407.

Busby, A. T., Ayllón, N., Kocan, K. M., Blouin, E. F., De La Fuente, G. et al. (2012). Expression of heat shock proteins and subolesin affects stress responses, Anaplasma phagocytophilum infection and questing behaviour in the tick, Ixodes scapularis. Medical and Veterinary Entomology, 26(1), 92-102.

Casey, T. M. (1988). Thermoregulation and heat exchange. Advances in Insect Physiology, 20, 119-146.

Center for Disease Control and Prevention, 2019. West Nile virus and other domestic nationally https://www.cdc.gov/mmwr/volumes/68/wr/mm6831a1.htm?s_cid=mm6831a1_e\&deliveryNam e=USCDC_921-DM6573. of Aedes aegypti mosquitoes in Trinidad. Journal of Vector Ecology, 27, 172-177. of endemic St Louis encephalitis virus strains by local Culex quinquefasciatus populations in Cordoba, Argentina. Transactions of the Royal Society of Tropical Medicine and Hygiene, 107(5), 332-334. quinquefasciatus in Raipur city of Chattisgarh state. The Journal of Communicable Diseases, 33(1), 17-22. gland antigens of Culex quinquefasciatus are D7-related proteins. Insect biochemistry and molecular biology, 33(1), 63-71. winter moths. Journal of Experimental Biology, 135(1), 109-117. 

mosquitoes and human disease: a review of the role of Culex pipiens complex mosquitoes in epidemiology. Infection, genetics and evolution, 11(7), 1577-1585. (2010). Host-feeding preference of the mosquito, Culex quinquefasciatus, in Yucatan State, Mexico. Journal of Insect Science, 10.

Grossman, G. L., \& Pappas, L. G. (1991). Human skin temperature and mosquito (Diptera:

Guilfoile, P. G., \& Packila, M. (2004). Identification of four genes expressed by feeding, female Ixodes scapularis including three with sequence similarity to previously recognized genes. Experimental \& applied acarology, 32(1-2), 103-110.

Gulia-Nuss, M., Elliot, A., Brown, M. R., \& Strand, M. R. (2015). Multiple factors contribute to anautogenous reproduction by the mosquito Aedes aegypti. Journal of insect physiology, 82, 8-16.

Hamon, J. (1963). Les moustiques anthropophiles de la région de Bobo Dioulasso, République de Haute Volta. Annals de la Société Entomologique de France. 85-145.

Headlee, T. J. (1914). Some data on the effect of temperature and moisture on the rate of insect metabolism. Journal of Economic Entomology, 7, 413.

Heinrich, B. (1976). Heat exchange in relation to blood flow between thorax and abdomen in bumblebees. Journal of Experimental Biology, 64(3), 561-585.

Heinrich, B. (1980a). Mechanisms of body-temperature regulation in honeybees, Apis mellifera: 85, 73-87.

Heinrich, B. (1995). Insect thermoregulation. Endeavour, 19(1), 28-33. 677-688. 

Molecular detection of flaviviruses and alphaviruses in mosquitoes (Diptera: Culicidae) from coastal ecosystems in the Colombian Caribbean. Memórias do Instituto Oswaldo Cruz, 111(10), 625-634.

Kemp, D. J., \& Krockenberger, A. K. (2004). Behavioural thermoregulation in butterflies: the interacting effects of body size and basking posture in Hypolimnas bolina (L.)(Lepidoptera: Nymphalidae). Australian journal of Zoology, 52(3), 229-239.

Kent, R. J., Crabtree, M. B., \& Miller, B. R. (2010). Transmission of West Nile virus by Culex quinquefasciatus (Say) infected with Culex Flavivirus Izabal. PLoS neglected tropical diseases, $4(5)$.

Kikuchi, K., Stremler, M. A., Chatterjee, S., Lee, W. K., Mochizuki, O. et al. (2018). Burst mode pumping: A new mechanism of drinking in mosquitoes. Scientific reports, 8(1), 1-15.

Lahondère, C., \& Lazzari, C. R. (2012). Mosquitoes cool down during blood feeding to avoid overheating. Current biology, 22(1), 40-45.

Lahondère, C., \& Lazzari, C. R. (2013). Thermal stress and thermoregulation during feeding in mosquitoes. In Anopheles mosquitoes - New insights into malaria vectors. IntechOpen. Glossina morsitans morsitans. Journal of thermal biology, 48, 45-50. exchange and thermoregulation during blood-feeding in kissing bugs. Elife, 6, e26107.

Lazzari, C.R., Fauquet, A., Lahondère, C, Araujo, R. \& M.H. Pereira. Soft ticks perform evaporative cooling during https://doi.org/10.1101/2020.06.30.180968. 
Meyer, R. P., Hardy, J. L., \& Presser, S. B. (1983). Comparative vector competence of Culex tarsalis and Culex quinquefasciatus from the Coachella, Imperial, and San Joaquin Valleys of California for St. Louis encephalitis virus. The American journal of tropical medicine and hygiene, 32(2), 305-311.

Molaei, G., Andreadis, T. G., Armstrong, P. M., Bueno Jr, R., Dennett, J. A. et al. (2007). Host feeding pattern of Culex quinquefasciatus (Diptera: Culicidae) and its role in transmission of West Nile virus in Harris County, Texas. The American journal of tropical medicine and hygiene, 77(1), 73-81.

Newman, C. M., Cerutti, F., Anderson, T. K., Hamer, G. L., Walker, E. D. et al. (2011). Culex Chicago, United States. Vector-Borne and Zoonotic Diseases, 11(8), 1099-1105. First isolation of Japanese encephalitis from Culex quinquefasciatus in Thailand. Southeast Asian journal of tropical medicine and public health, 36(4), 875.

Oduola, A. O., \& Awe, O. O. (2006). Behavioural biting preference of Culex quinquefasciatus in human host in Lagos metropolis Nigeria. Journal of vector borne diseases, 43(1), 16.

Oleaga, A., Obolo-Mvoulouga, P., Manzano-Román, R., \& Pérez-Sánchez, R. (2017). Functional annotation and analysis of the Ornithodoros moubata midgut genes differentially expressed after blood feeding. Ticks and tick-borne diseases, 8(5), 693-708. evaluation of Heat Shock Proteins 70 (HSP70/HSC70) on Rhodnius prolixus (Hemiptera, Reduviidae) physiological responses associated with feeding and starvation. Insect Biochemistry and Molecular Biology, 77, 10-20. Blood-Feeding in Arthropods. In Heat Shock Proteins in Veterinary Medicine and Sciences (pp. 349-359). Springer, Cham. albopictus in Thailand. Journal of medical entomology, 42(5), 844-849. 
R: A language and environment for statistical computing. R Foundation for Statistical Computing, Vienna, Austria. URL http://www.R-project.org/. patterns of blood-feeding by kissing-bugs (Hemiptera: Reduviidae: Triatominae). Memorias Do Instituto Oswaldo Cruz, 106(4), 479-494. of Entomology, 52, 351-374.

Reinhold, J. M., Lazzari, C. R., \& Lahondère, C. (2018). Effects of the environmental temperature on Aedes aegypti and Aedes albopictus mosquitoes: a review. Insects, 9(4), 158. haematophagous insect Rhodnius prolixus: effect of starvation and temperature. Journal of Experimental Biology, 217(24), 4414-4422. Thermal stress responses of Sodalis glossinidius, an indigenous bacterial symbiont of hematophagous tsetse flies. PLoS neglected tropical diseases, 13(11), e0007464. Psychodidae). European Journal of Entomology, 95(4), 643-647. change influences on the global potential distribution of the mosquito Culex quinquefasciatus, vector of West Nile virus and lymphatic filariasis. PloS one, 11(10).

Sasaki, H., Rosales, R., \& Tabaru, Y. (2003). Host feeding profiles of Rhodnius prolixus and Triatoma dimidiata in Guatemala (Hemiptera: Reduviidae: Triatominae). Medical Entomology and Zoology, 54(3), 283-289. choice and West Nile virus infection rates in blood-fed mosquitoes, including members of the Culex pipiens complex, from Memphis and Shelby County, Tennessee, 2002-2003. Vector-Borne and Zoonotic Diseases, 7(3), 365-386. adultes. Cahiers ORSTOM. Série Entomologie Médicale et Parasitologie. 8, 353-376. 
544 Subra, R. (1981). Biology and control of Culex pipiens quinquefasciatus* Say, 1823 (Diptera, 545 Culicidae) with special reference to Africa. International Journal of Tropical Insect Science, 1(4), $546 \quad 319-338$.

548 Thomas, S., Ravishankaran, S., Justin, N. J. A., Asokan, A., Mathai, M. T. et al. (2017). Resting 549 and feeding preferences of Anopheles stephensi in an urban setting, perennial for malaria. Malaria 550 journal, 16(1), 1-7.

Triteeraprapab, S., Kanjanopas, K., Suwannadabba, S., Sangprakarn, S., Poovorawan, Y., et al. (2000). Transmission of the nocturnal periodic strain of Wuchereria bancrofti by Culex quinquefasciatus: establishing the potential for urban filariasis in Thailand. Epidemiology \& Infection, 125(1), 207-212. Effects on the Activity of a Laboratory Strain of Aedes aegypti. Insects, 10(10), 347. host learning in Aedes aegypti mosquitoes. Current Biology, 28(3), 333-344.

Vinogradova, E. B. (2000). Culex pipiens pipiens mosquitoes: taxonomy, distribution, ecology, physiology, genetics, applied importance and control (No. 2). Pensoft Publishers. 22(1), 83-85.

Wang, Z., Zhang, X., Li, C., Zhang, Y., Xing, D. et al. (2012). Vector competence of five common mosquito species in the People's Republic of China for Western equine encephalitis virus. VectorBorne and Zoonotic Diseases, 12(7), 605-608. 6), 711. 
Table 1: Summary of the feeding behavior and physiological characteristics of several bloodsucking arthropods. (*) indicates that HSPs are synthesized by a closely related species. Numbers in parentheses indicate the reference of the studies.

586

\begin{tabular}{|c|c|c|c|c|c|c|}
\hline & $\begin{array}{c}\text { Feeding } \\
\text { Duration }\end{array}$ & $\mathbf{T}_{b}-\mathbf{T}_{h}$ & $\mathbf{T}_{b}-\mathbf{T}_{a b}$ & $\begin{array}{l}\text { Cooling } \\
\text { method }\end{array}$ & HSPs & Preferred Host \\
\hline $\begin{array}{c}\text { Cx. } \\
\text { quinquefasciatus }\end{array}$ & $>3 \min (1)$ & $\sim 6^{\circ} \mathrm{C}(1)$ & $\sim 8^{\circ} \mathrm{C}(1)$ & $\begin{array}{l}\text { evaporative } \\
\text { cooling (1) }\end{array}$ & $\begin{array}{c}\text { unknown* } \\
\text { (2) }\end{array}$ & $\begin{array}{c}\text { birds (3), humans } \\
\text { (4) }\end{array}$ \\
\hline Cx. pipiens & $\sim 3 \min (2)$ & -- & -- & unknown & yes (2) & $\begin{array}{l}\text { birds, small } \\
\text { mammals (5) }\end{array}$ \\
\hline Cx. territans & $\begin{array}{c}>40 \min \\
(6)\end{array}$ & $\begin{array}{l}\text { negligible } \\
\text { (6) }\end{array}$ & $\begin{array}{l}\text { negligible } \\
\text { (6) }\end{array}$ & unknown & unknown & amphibians (5) \\
\hline Ae. aegypti & $\begin{array}{c}1.5-3.5 \mathrm{~min} \\
(7,8)\end{array}$ & $1-2^{\circ} \mathrm{C}(9)$ & $10^{\circ} \mathrm{C}(9)$ & unknown & yes (2) & $\begin{array}{l}\text { humans, other } \\
\text { mammals (10) }\end{array}$ \\
\hline An. stephensi & $2-4 \min (9)$ & $1-6^{\circ} \mathrm{C}(9)$ & $4-10^{\circ} \mathrm{C}(9)$ & $\begin{array}{l}\text { evaporative } \\
\text { cooling (9) }\end{array}$ & $\begin{array}{l}\text { unknown* } \\
\text { (2) }\end{array}$ & cattle (11) \\
\hline $\begin{array}{c}\text { Glossina } \\
\text { morsitans }\end{array}$ & $\begin{array}{l}0.5-1 \mathrm{~min} \\
\quad(12)\end{array}$ & $\begin{array}{c}0.1-2.5^{\circ} \mathrm{C} \\
\quad(12)\end{array}$ & $\begin{array}{c}0.7-3.6^{\circ} \mathrm{C} \\
(12)\end{array}$ & unknown & yes (13) & $\begin{array}{c}\text { mammals, } \\
\text { primarily } \\
\text { ungulates (14) }\end{array}$ \\
\hline $\begin{array}{l}\text { Rhodnius } \\
\text { prolixus }\end{array}$ & $\begin{array}{c}>10 \min \\
(15)\end{array}$ & $\begin{array}{c}\sim 5^{\circ} \mathrm{C} \\
(15)\end{array}$ & $\sim 12^{\circ} \mathrm{C}(15)$ & $\begin{array}{l}\text { Countercurrent } \\
\text { heat exchange } \\
\text { (15) }\end{array}$ & yes (15) & $\begin{array}{l}\text { humans, other } \\
\text { mammals, birds } \\
\text { (16) }\end{array}$ \\
\hline Cimex lectularius & $7.5 \min (2)$ & -- & -- & unknown & yes (2) & humans, bats (17) \\
\hline $\begin{array}{c}\text { Ornithodoros } \\
\text { rostratus }\end{array}$ & $\begin{array}{l}15 \min \\
(18)\end{array}$ & -- & $3^{\circ} \mathrm{C}(18)$ & $\begin{array}{l}\text { evaporative } \\
\text { cooling (18) }\end{array}$ & $\begin{array}{c}\text { unknown* } \\
\text { (19) }\end{array}$ & mammals (18) \\
\hline
\end{tabular}

References: (1) This study; (2) Benoit et al., 2011; (3) Dixit et al., 2001 ; (4) Garcia-Rejon et al., 2010; (5) Savage et al., 2007 ; (6) Personal observation; (7) Mellink I, 1982; (8) Grossman and Pappas, 1991; (9) Lahondère and Lazzari, 2012; (10) Ponlawat and Harrington, 2005; (11) Thomas et al., 2017; (12) Lahondère and Lazzari, 2015; (13) Roma et al., 2019; (14) Weitz, 1963; (15) Lahondère et al., 2017; (16) Sasaki et al., 2003; (17) Balvin et al., 2012 ; (18) Lazzari et al., 2020 ; (19) Oleaga et al., 2017. 


\section{Figure captions}

Figure 1: Schematic of the experimental blood feeding setup: 1. Water bath; 2. Tubing connecting water bath to blood feeder; 3. Blood feeder, containing cow's blood; 4. Cage containing several female $C x$. quinquefasciatus mosquitoes; 5. FLIR thermographic camera; 6. Laptop containing ResearchIR software for video analysis.

615 Figure 2: Thermographic images of $C x$. quinquefasciatus female mosquitoes taken shortly after landing on the blood-feeder $(\mathbf{A})$, during blood-feeding ( Tblood $\left.=37 \pm 1^{\circ} \mathrm{C}\right)(\mathbf{B})$, and after feeding (C) and their respective body temperatures (A', B', C').

Figure 3: Evolution of the temperature of the head (yellow), thorax (orange) and abdomen (red) of a $C x$. quinquefasciatus female during feeding on a blood-meal at $37 \pm 1^{\circ} \mathrm{C}$. Recordings were conducted at 30 frames / sec.

Figure 4: Average temperatures of the head, thorax and abdomen of $C x$ quinquefasciatus females $(\mathrm{N}=10)$ feeding on a blood-meal at $37 \pm 1{ }^{\circ} \mathrm{C}$. Vertical bars represent the standard error of the mean values (S.E.M.) Letters above the error bars indicate statistical differences (Student $t$-tests, $\mathrm{p}<0.001)$.

Figure 5: A. Thermographic image of a $C x$. quinquefasciatus female during feeding on a bloodmeal at $37 \pm 1{ }^{\circ} \mathrm{C}$ producing and maintaining a droplet of urine at the tip of its abdomen, indicated by the arrow. B. Evolution of the temperature of its abdominal temperature before the droplet emission / retention (red) and after (blue). The emission of the droplet occurs 60 seconds after starting feeding (black arrow) and remains attached until the female takes off. 
Figure 1

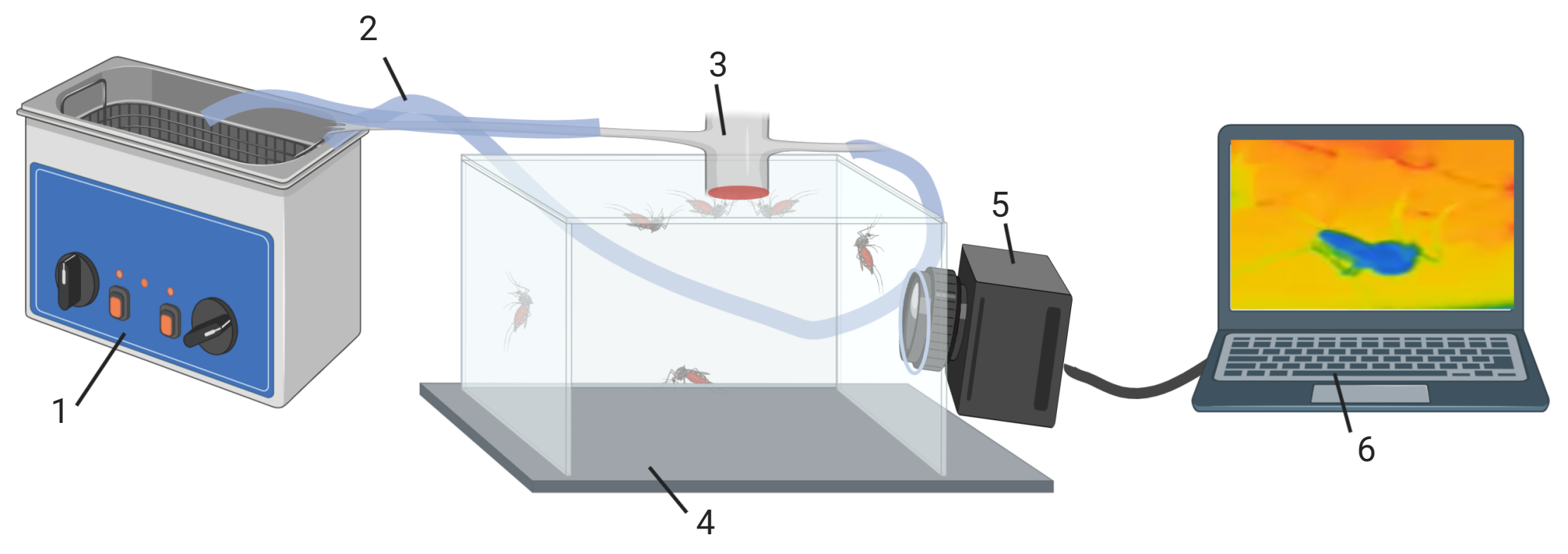


A

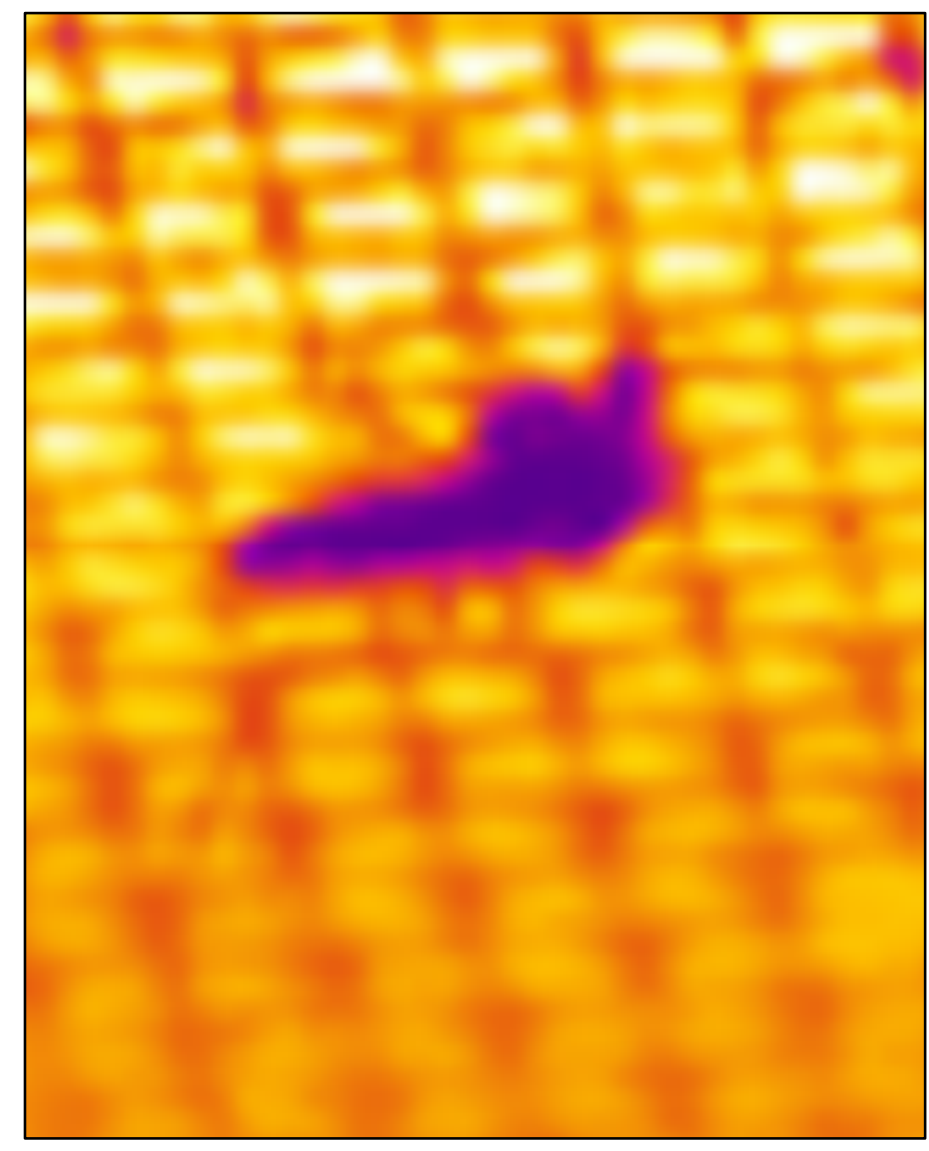

A $^{\prime} 32$

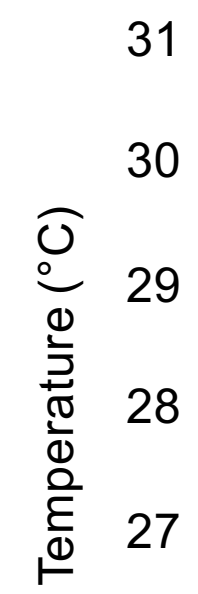

26

25

24
B

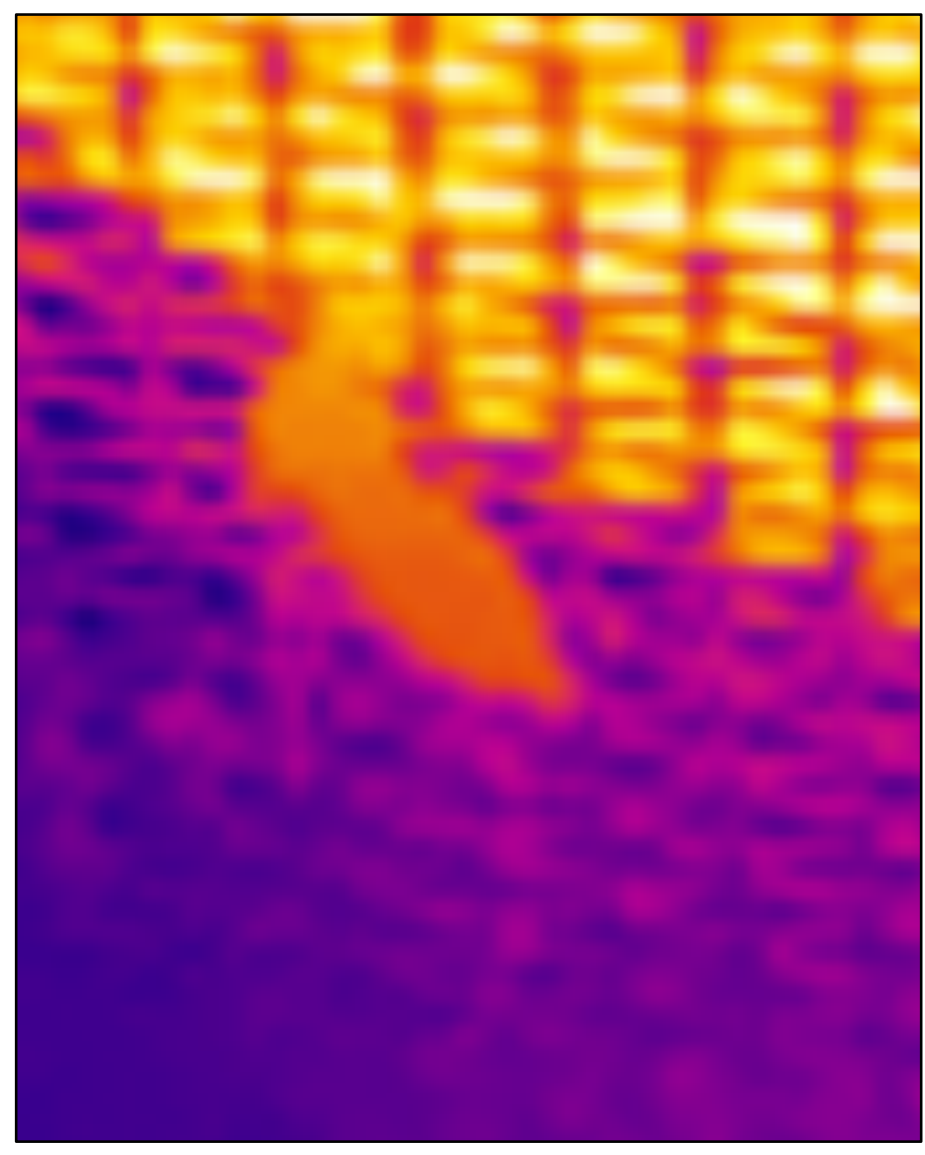

\section{B}

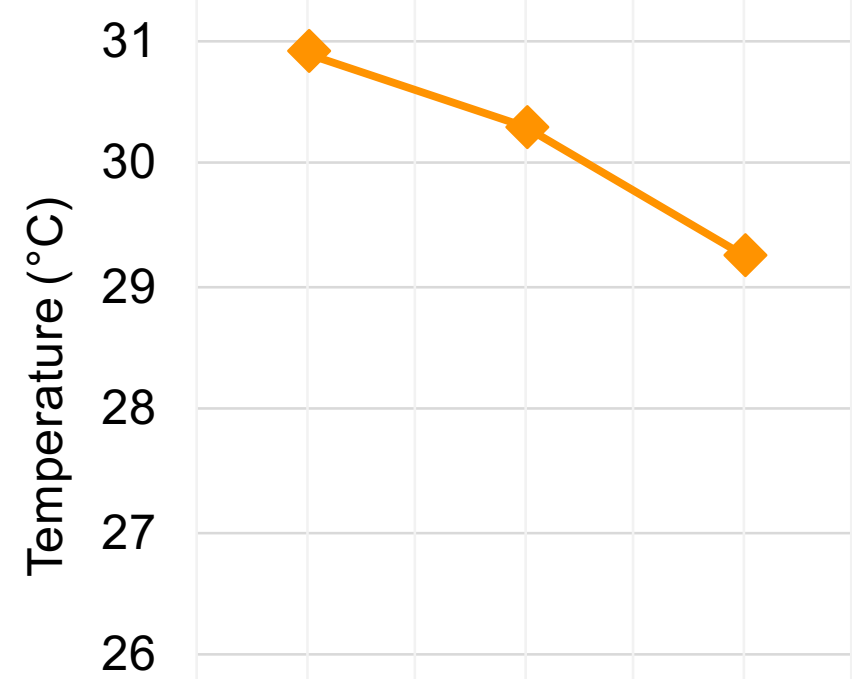

25

24
C

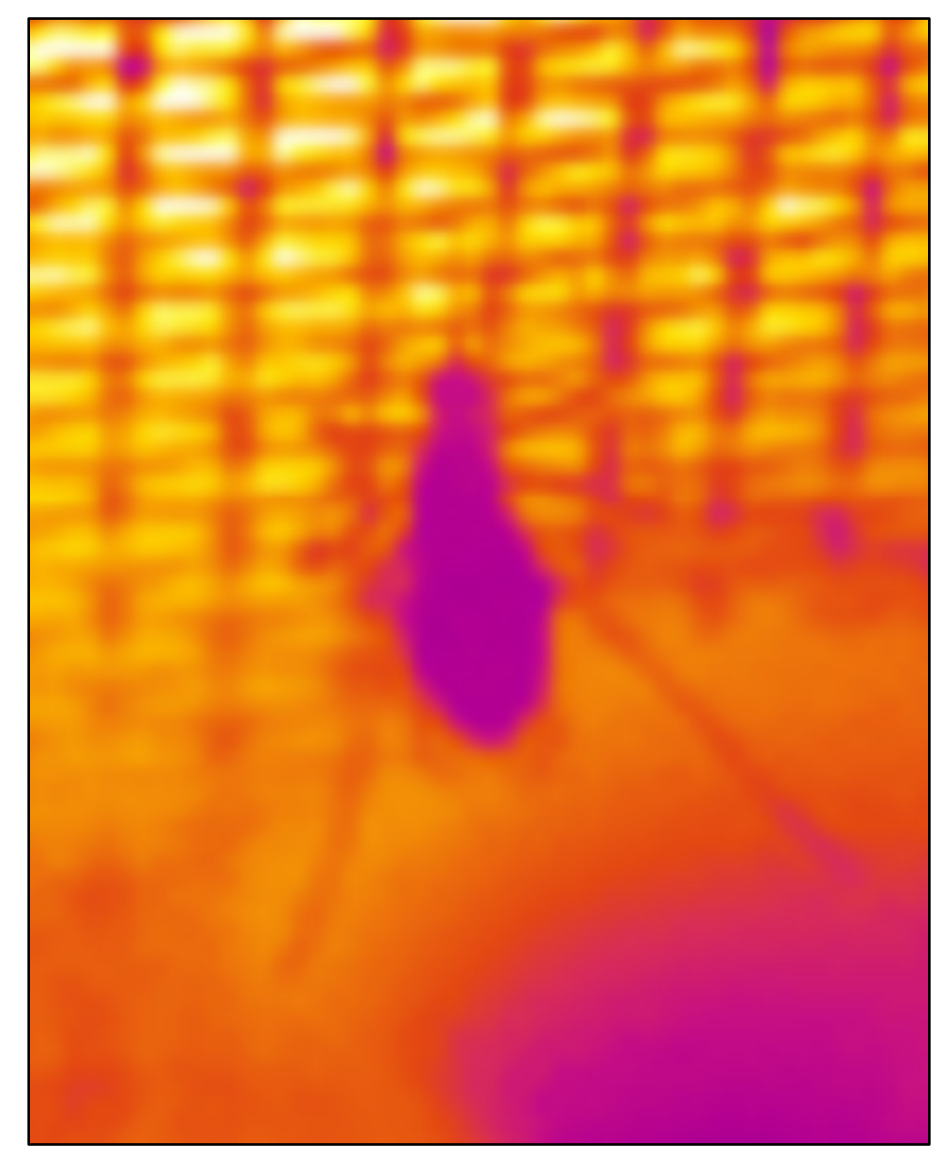

C' 32

31

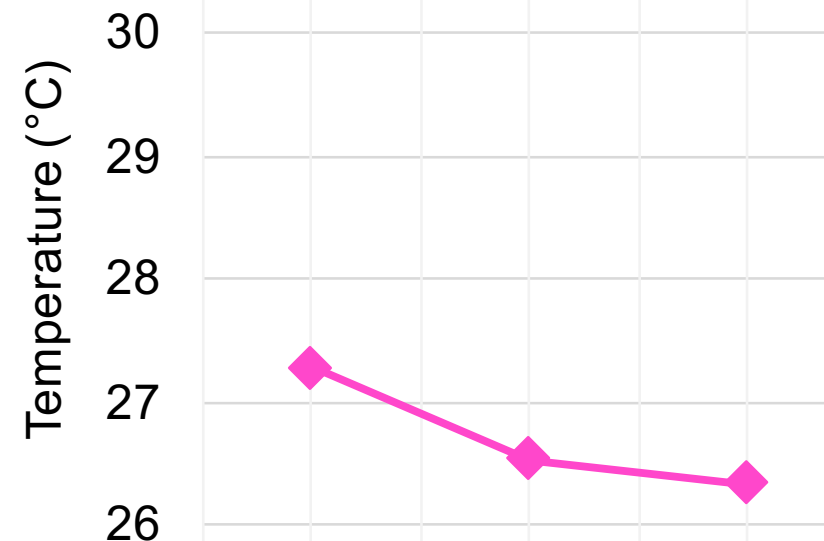

25

24

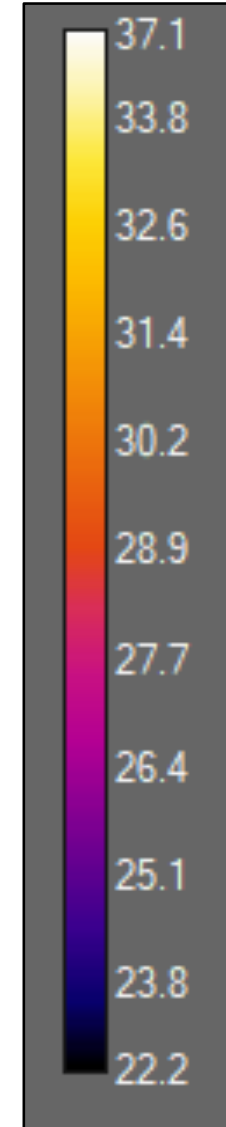

26.4
25.1
23.8
22.2

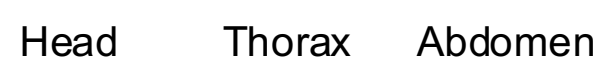

Head Thorax Abdomen

Head Thorax Abdomen 


\section{Figure 3}

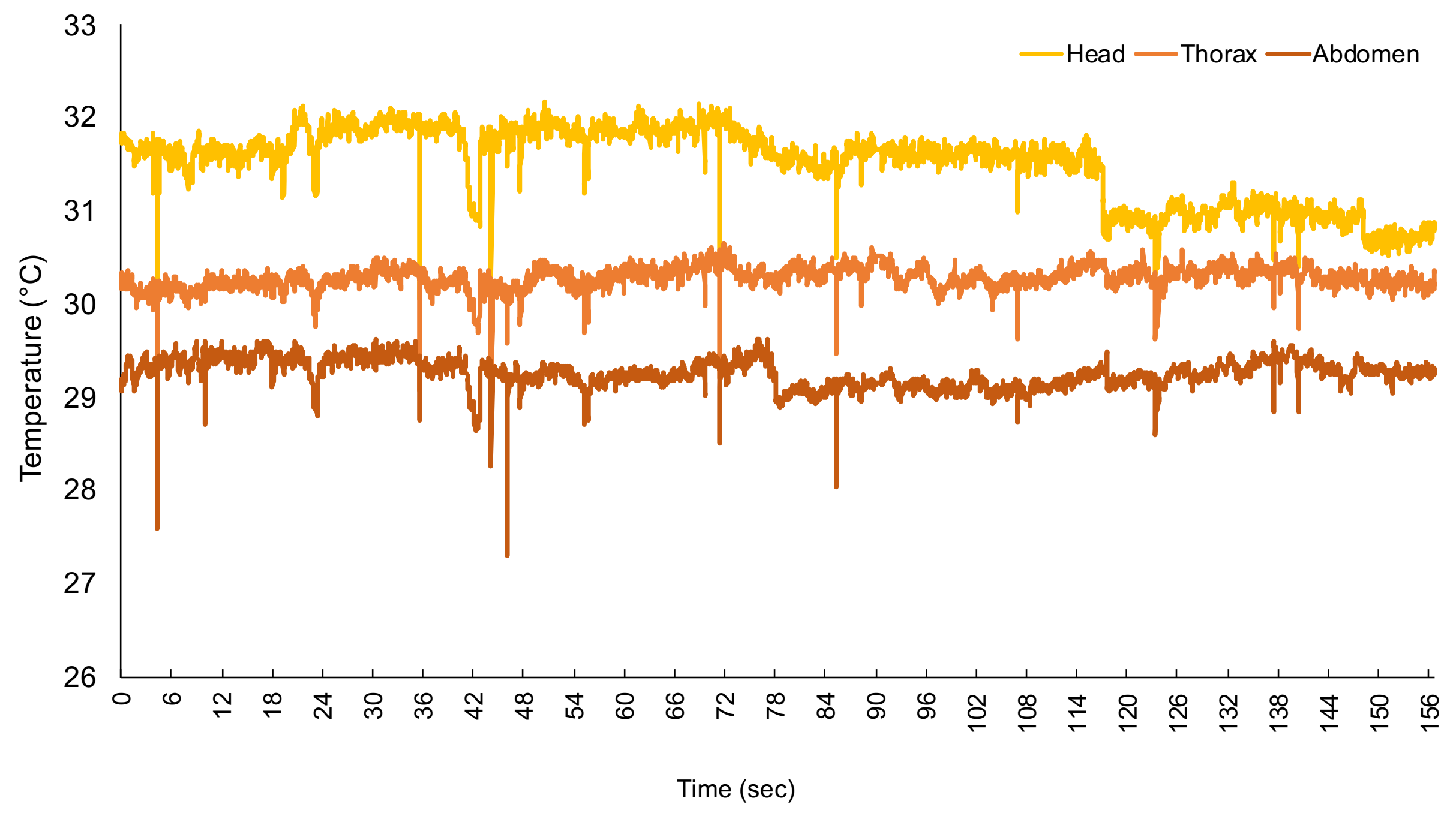




\section{Figure 4}

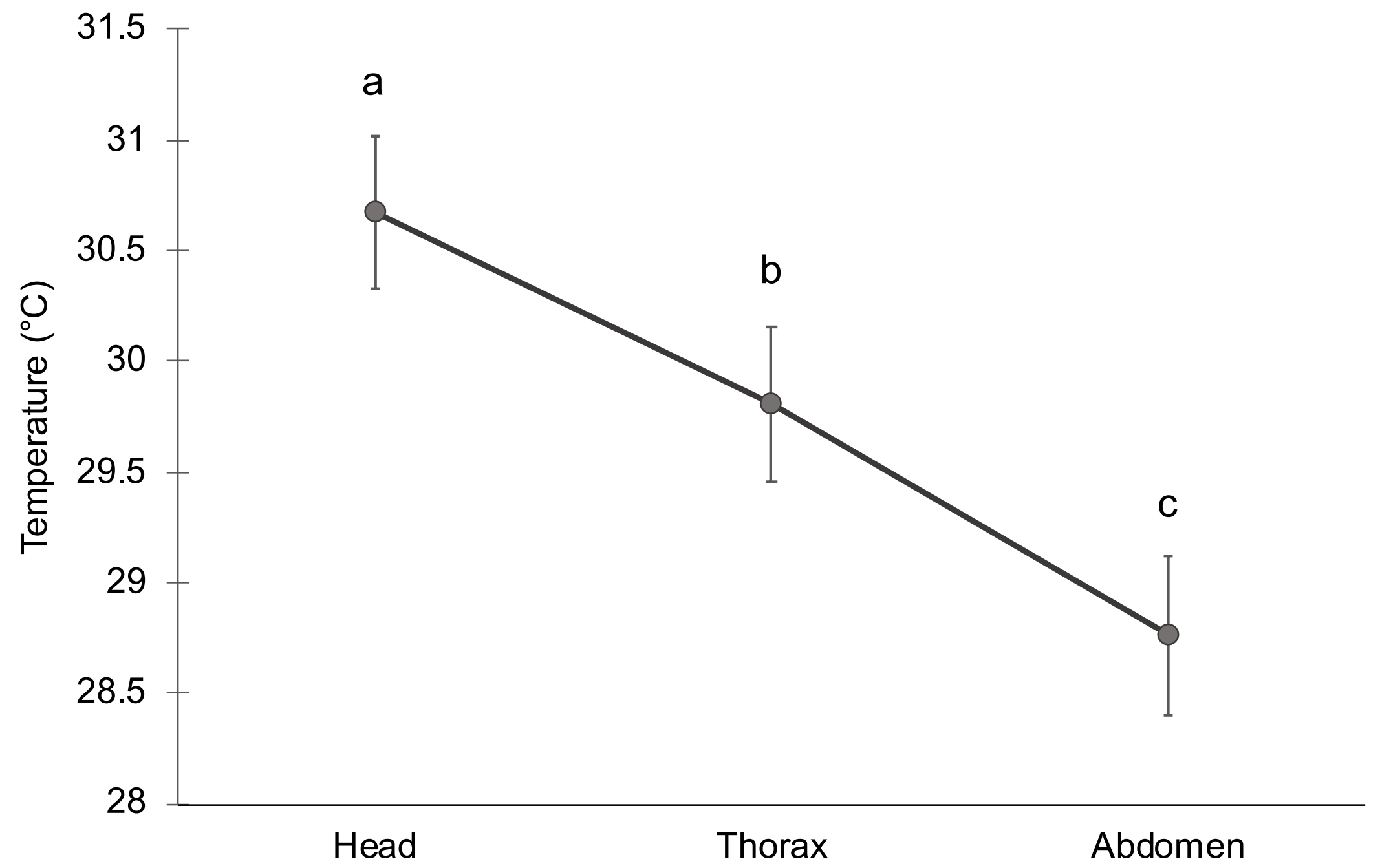




\section{Figure 5}

A

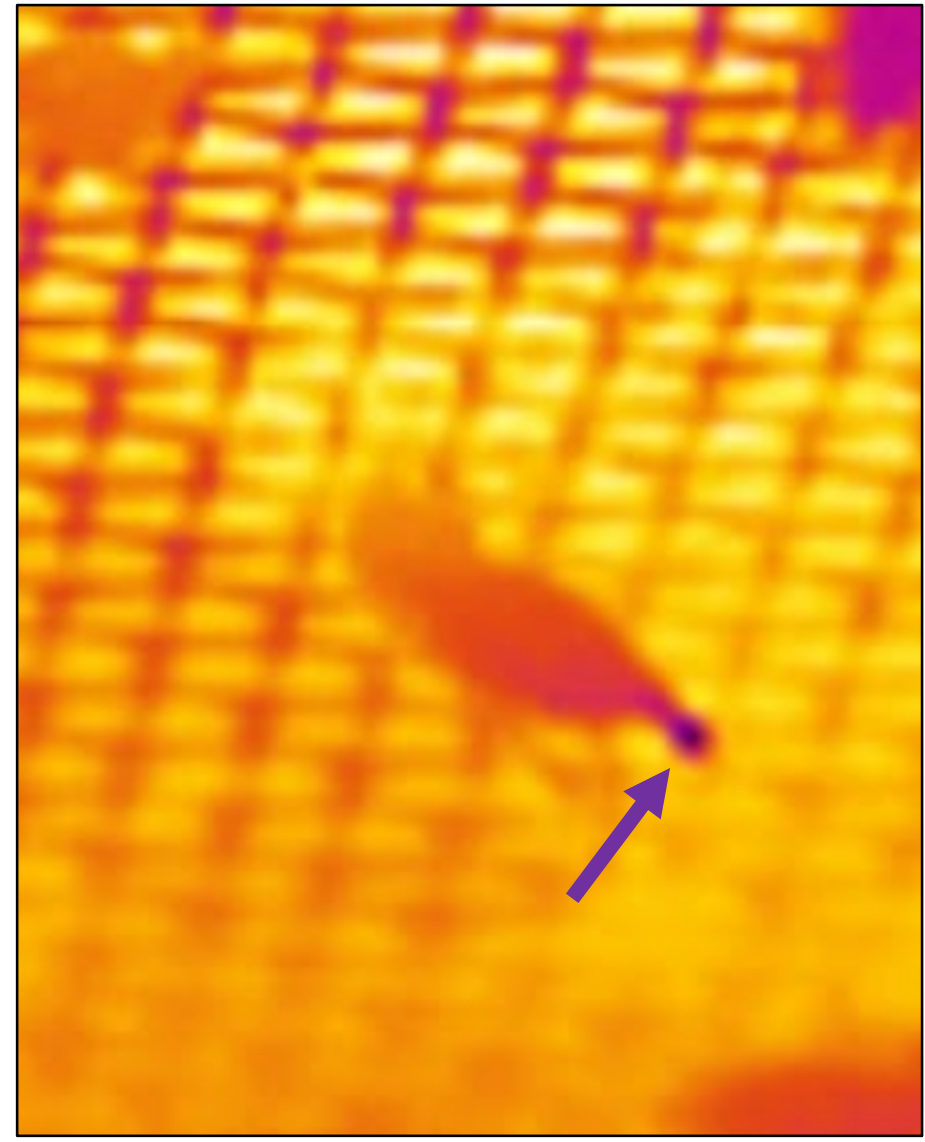

B

37.1
33.8
32.6
31.4
30.2
28.9
27.7
26.4
25.1
23.8
22.2

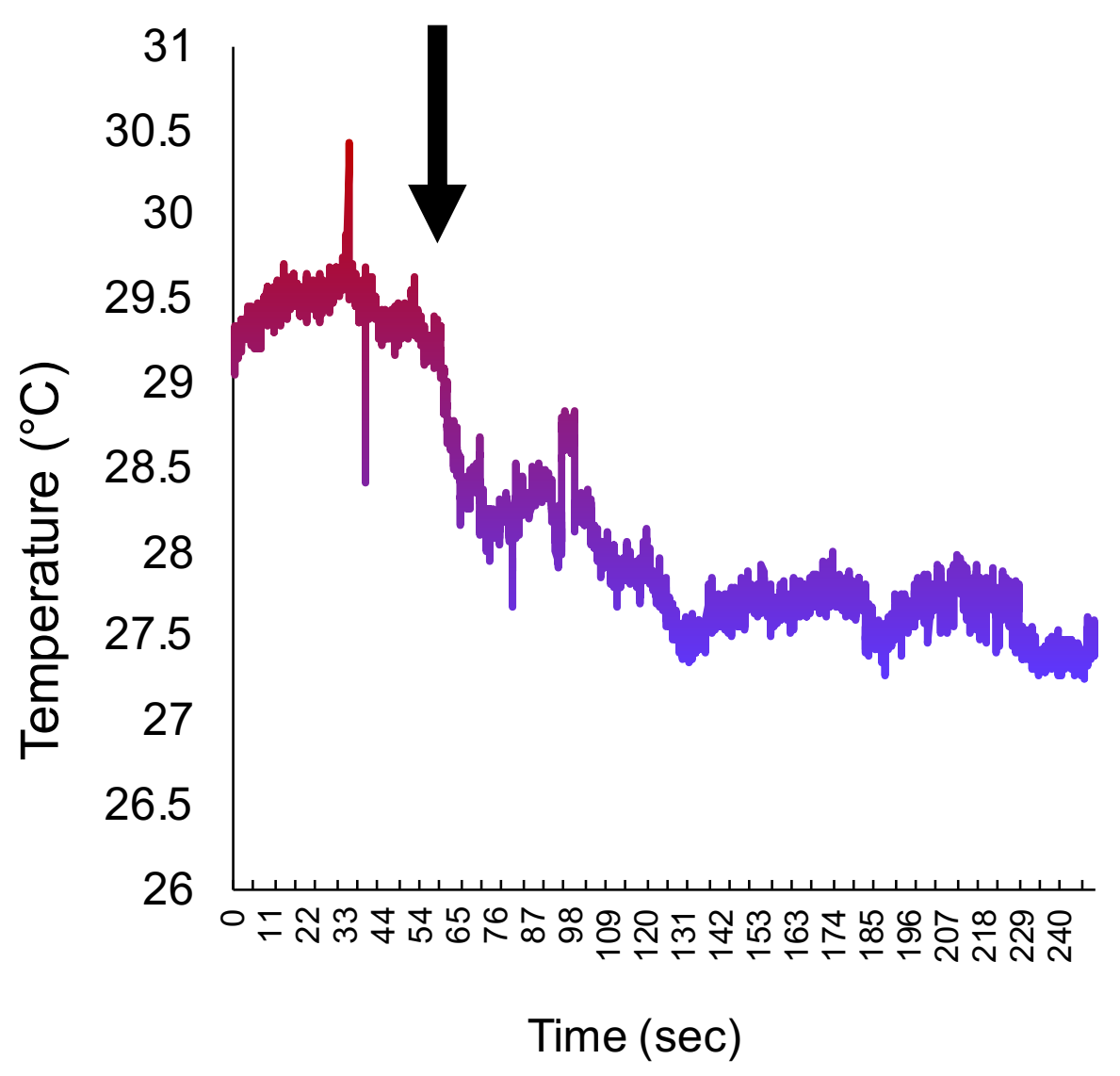

